Supplement of

\title{
The anisotropic properties of granites - effects of tectonic emplacement mode on potential crystalline host rocks for nuclear waste deposits in Germany
}

Uwe Kroner et al.

Correspondence to: Uwe Kroner (kroner@geo.tu-freiberg.de)

The copyright of individual parts of the supplement might differ from the article licence. 


\title{
THE ANISOTROPIC PROPERTIES OF GRANITES
}

\author{
Effects of tectonic emplacement mode on potential crystalline host rocks for nuclear waste \\ deposits in Germany
}

Uwe Kroner ${ }^{1}$, Peter Hallas ${ }^{2}$, Franz Müller ${ }^{1}$

1) Technische Universität Bergakademie Freiberg, Institut für Geologie, B.-v.-Cotta Str. 2, 09599 Freiberg

2) Thüringer Landesamt für Umwelt, Bergbau und Naturschutz, Außenstelle Weimar, Dienstgebäude 2, Carl-August-Allee 8 - 10, 99423 Weimar

For permanent nuclear waste disposals sites, crystalline rocks, and especially granite is considered as an appropriate host rock. Three principal types of granitic plutons occur in the extra-alpine crystalline basement of Germany, which were consolidated during the late Paleozoic Variscan orogeny of Central Europe.

i) Pre-Variscan voluminous granodiorites that are hardly affected by subsequent continent - continent collision.

ii) Voluminous granites in various tectonic settings intruded during the late-orogenic

stage of the Variscides.

iii) Post-orogenic granites related to vast Permian intracontinental extension.

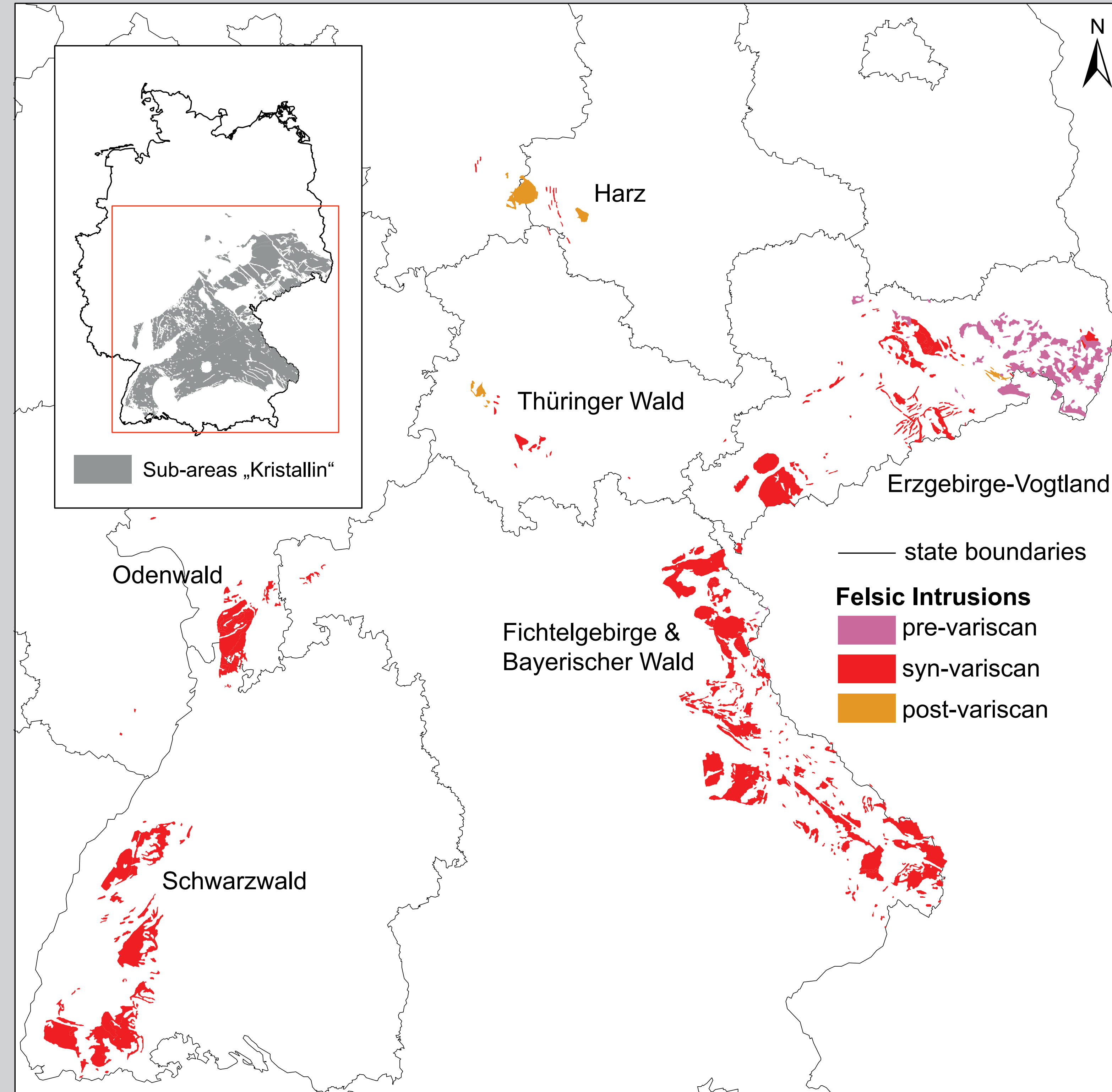

Fig. 1: Overview map of the felsic plutonites of Germany which are not covered.

Although it can be expected that different tectonic environments cause significant differences of the material properties, for Germany, however, there is no systematic study regarding the fabric of such plutonites. In order to find the most suitable "granite" we will investigate the primary anisotropy of granites evolved during the emplacement and crystallization of the melt. For this we sample rocks of all three principal types and various syn-intrusive tectonic settings, i.e., compression, extension, strike-slip, transtension and transpression.

By means of combined measurements of the "Anisotropy of the Magnetic Susceptibility" (AMS) and the "Shape Preferred Orientation" (SPO) we characterize the syn-intrusive flow pattern, i.e., the magmatic foliation and lineation. The Crystallographic Preferred Orientation (CPO) will be analyzed by the combination of neutron time-of-flight (ToF) experiments and electron backscatter diffraction (EBSD) measurements at the Frank Laboratory of Neutron Physics at JINR, Dubna, Russia and the TU Bergakademie Freiberg, respectively. This allows to obtain a wide range of texture information, from volume $\left(\sim 60 \mathrm{~cm}^{3}\right)$ to spatially resolved at sub-grain scale. Special attention lies on the systematic mapping of annealed microcracks evolved during late magmatic fluid escape and/or post-crystallization hydrothermal activity. These datasets will be organized in a geoscientific information system (GIS) allowing for a complete traceability of the different investigation steps. In a second step we compare the primary anisotropy with the post-magmatic fracture pattern of the particular granites. Those fractures constitute probable fluid pathways and, thus, the first order risk for a potential permanent nuclear waste disposal. Conclusions on the (re-)activation conditions of cracks derived from these datasets provide the basis for the future detailed exploration.

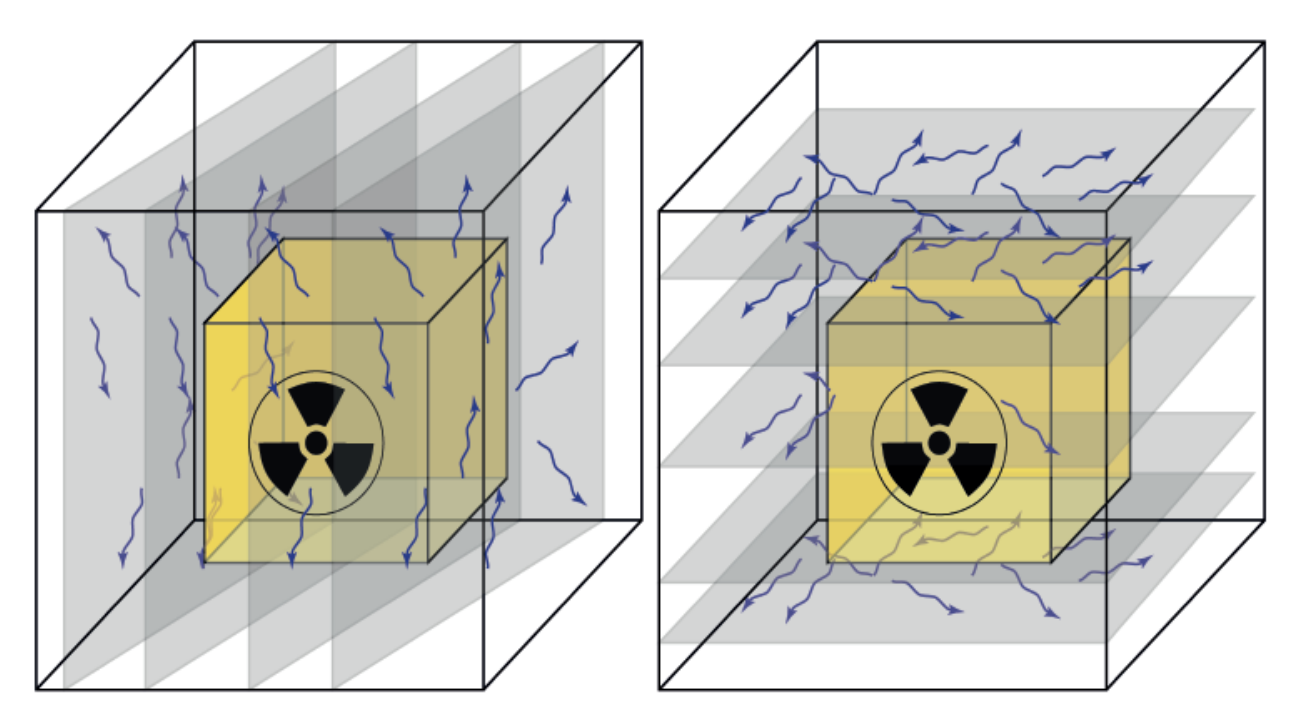

Fig. 2: Potential fluid pathways within granitic host rocks resulting from extensional fracturing are highly dependent on the anisotropic fabric of the granitic material. It is determined by various geological processes such as magmatic flow, static crystallisation, plastic deformation, post-intrusive hydrothermal processes, etc.

Primary Anisotropy
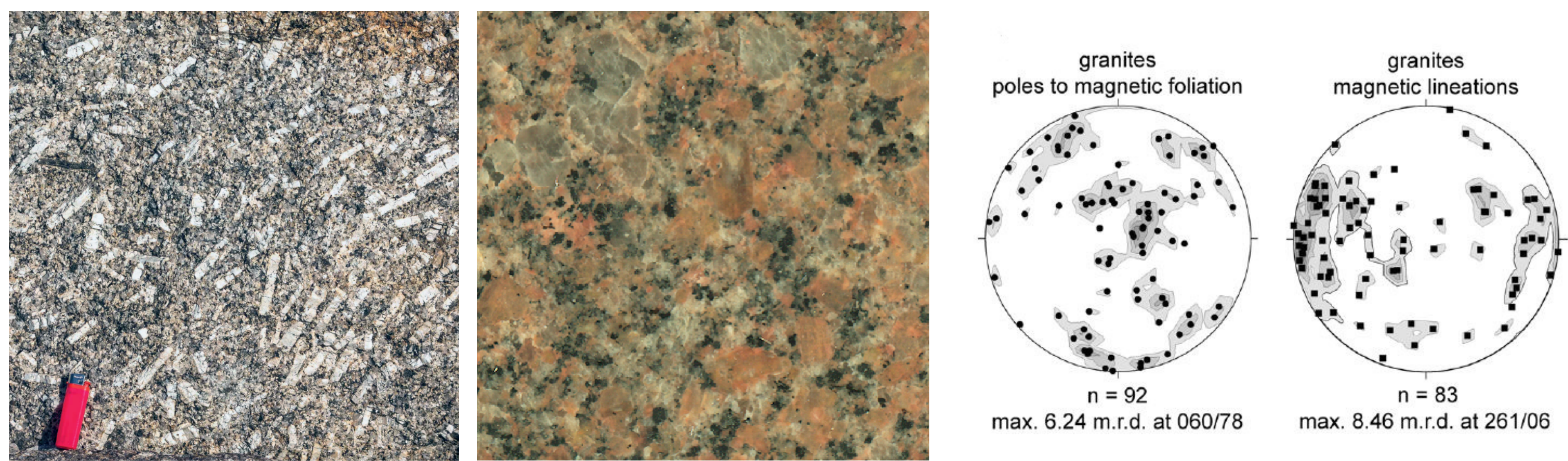

ig. 3: Strongly aligned magmatic flow fabric of a grantl England.

Fig. 4: Seemingly isotropic fabric of the Fig. 5 Stereograms of magnetic foliations and magnetic Niederbobritzsch granite. Despite the lineations restance granites are prima- et al. 2016.

Crystallographic preferred orientation of quartz in geographical reference

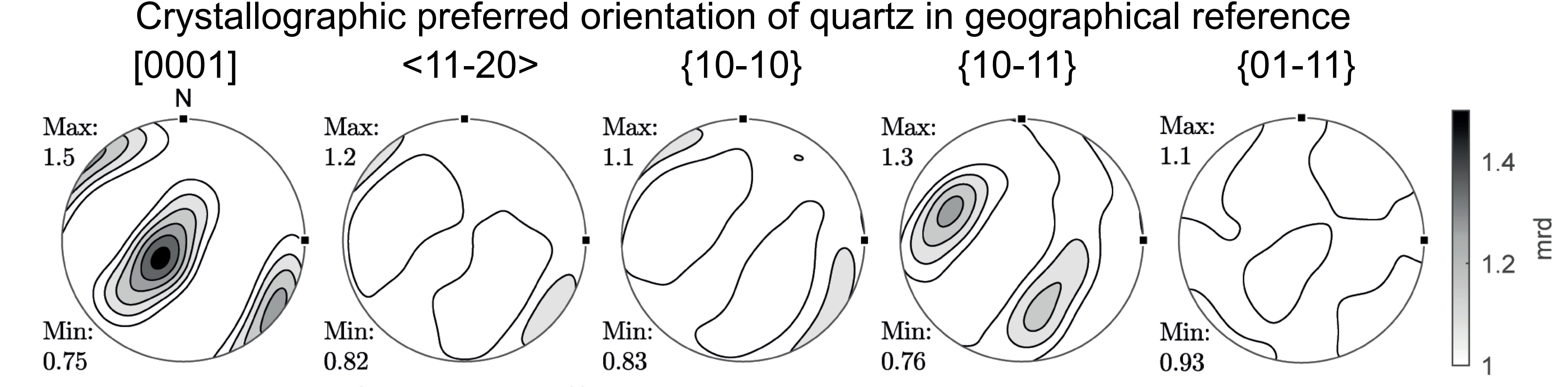

\section{Texture index: 104 , Uniform portion: $00.59 \%$}
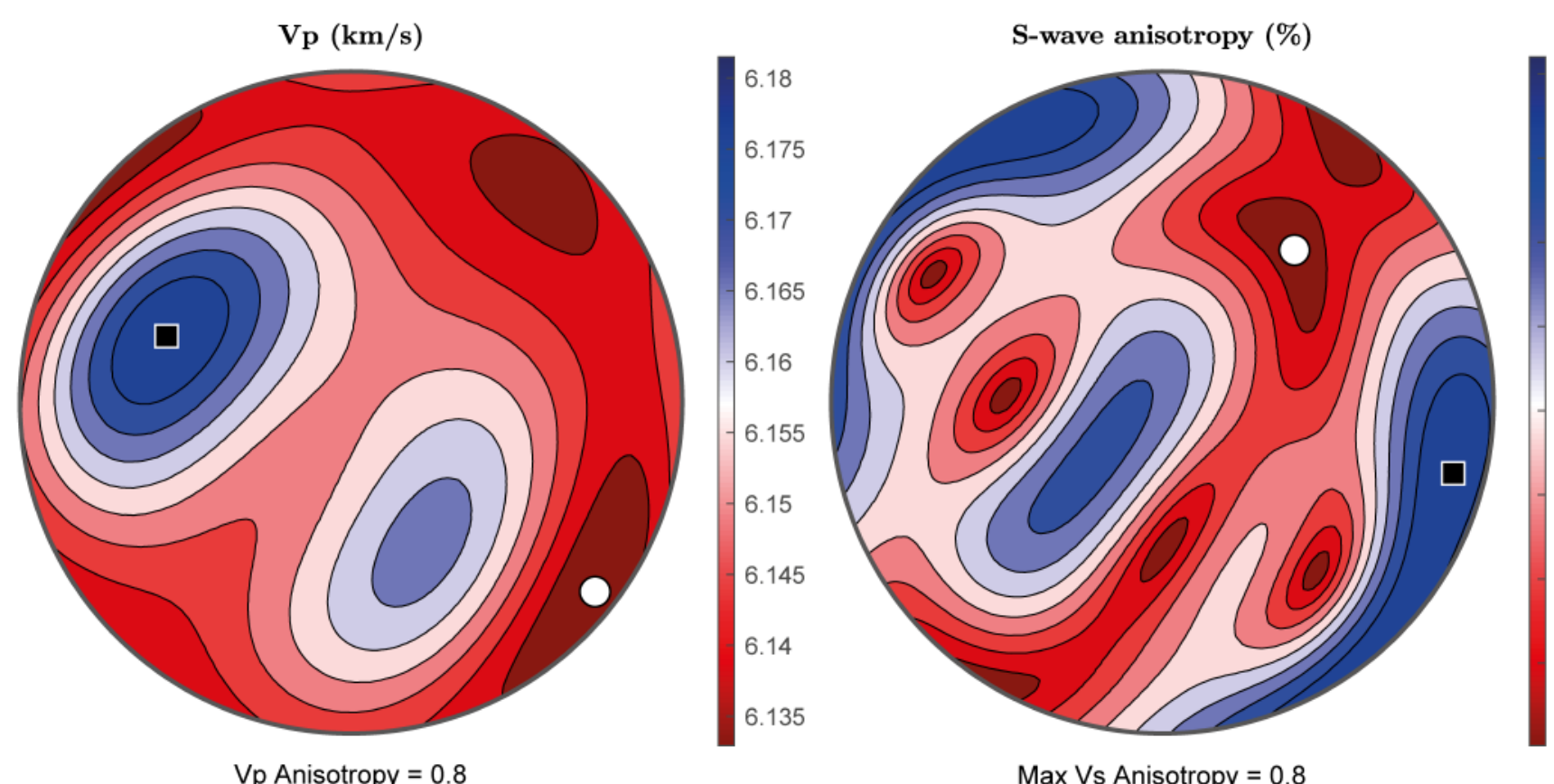

ig. 6 (above): Quartz volume texture of the Niederbobritzsch granite resulting
Russia).

Fig. 7 (left): Calculation of anisotropic seismic properties from texture data (see Mainprice et al. 2011). Displayed are P- and S-wave veloc

\section{(1)}

Late- to Postmagmatic Anisotropy
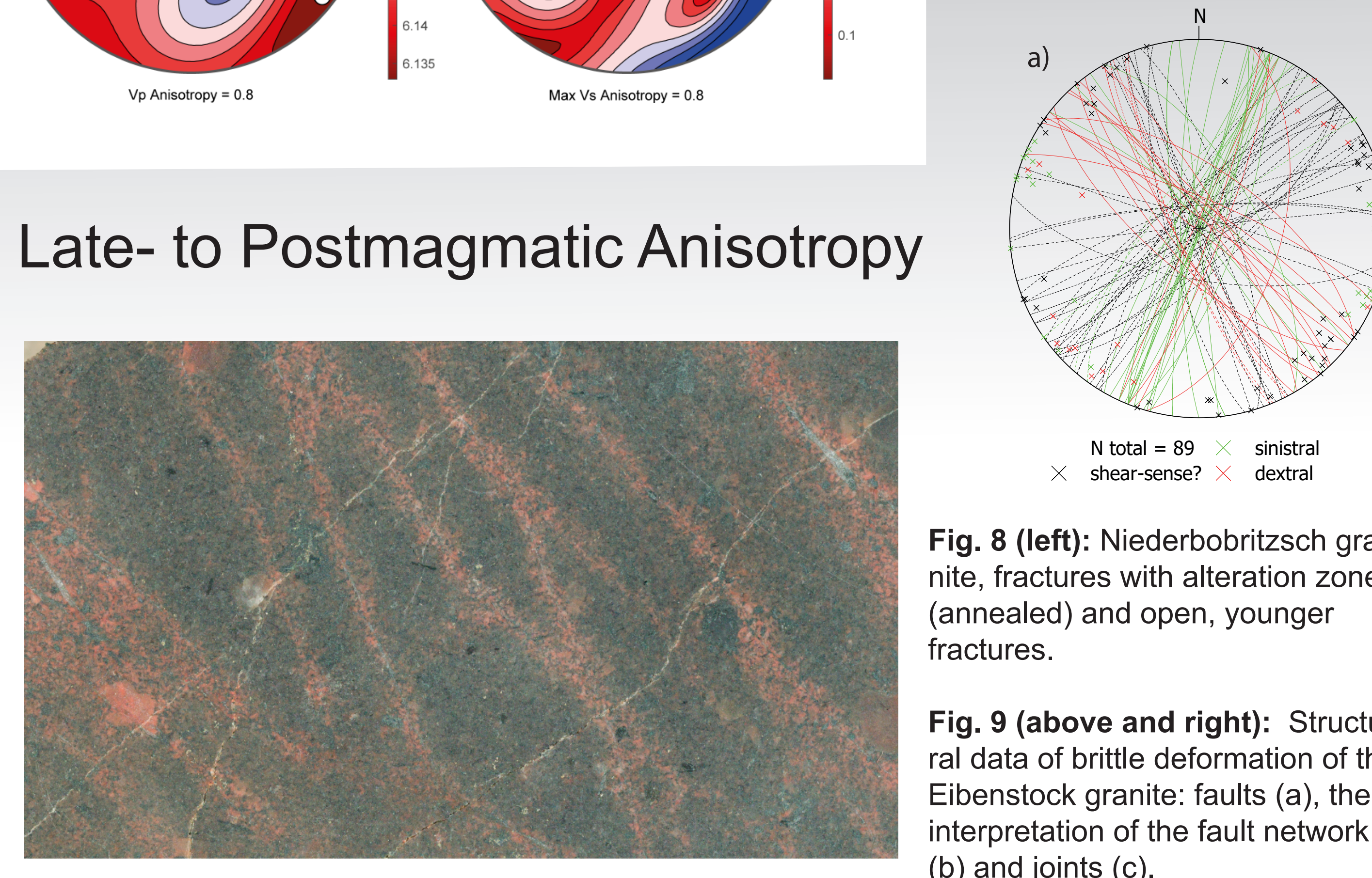

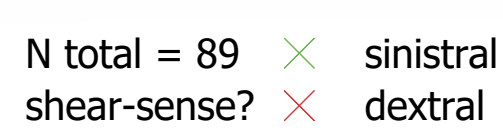

Fig. 8 (left): Niederbobritzch graannealed and open, younger ractures.

fig. 9 (above and right): StructuFing data of britte deformation of the interpretation of the fault (a), the (b) and joints (c)
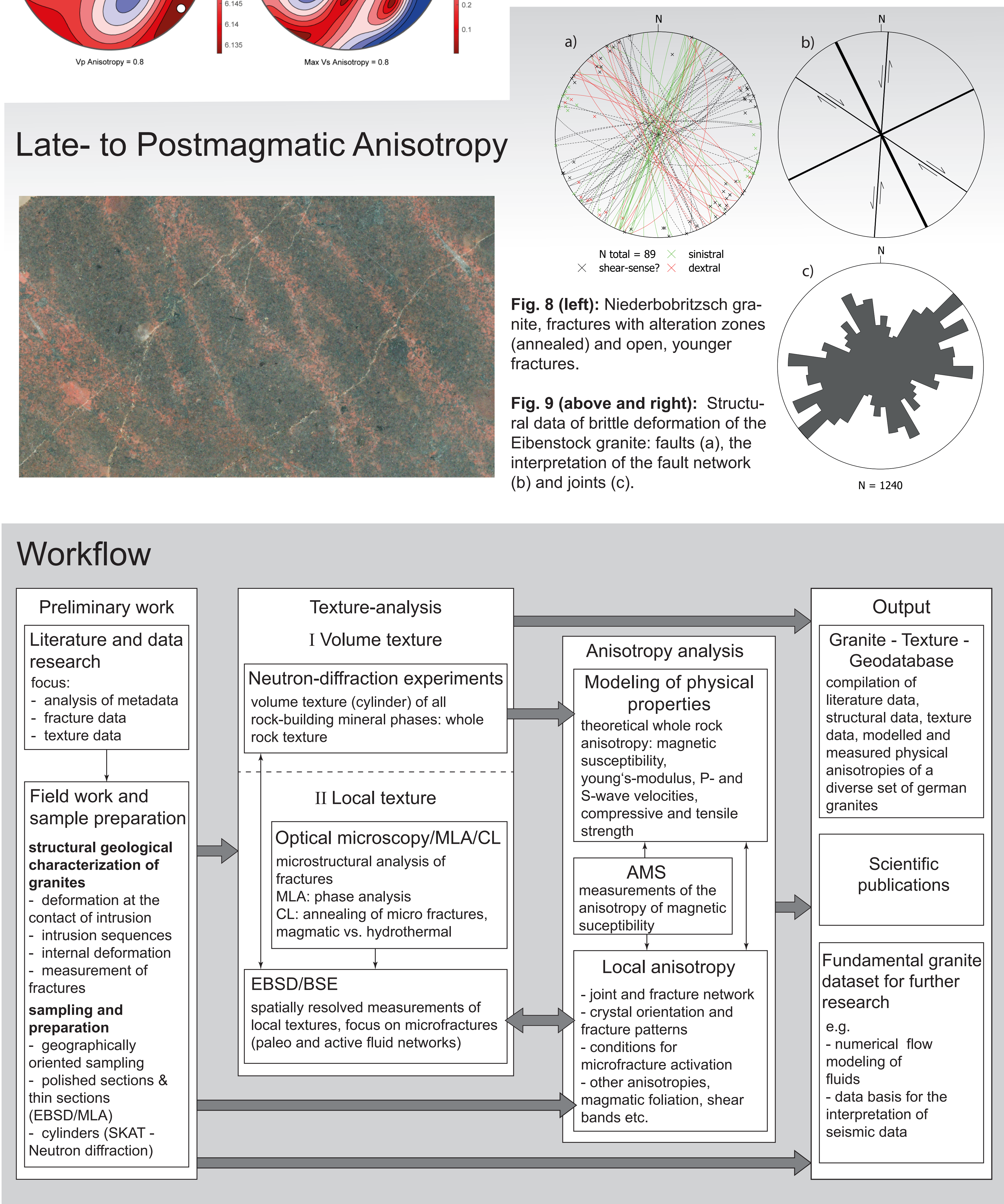

References

Grimmer, J., 1997, Granite is never isotropic. An introduction to AMS studies of granitic rocks, in Bouchez, J.L., Hullon, D., el al., eds., Granite: From Segregation of Melt to Emplacement Fabrics.: Dordrecht, Springer. Petro Mainprice, D., Hielscher, R., and Schaeben, H., 2011, Calculating anisotropic physical properties from texture data using the MTEX open-source package: Geological Society, London, Special Publications, v. 360, no. 1, p. 175-192. 